\title{
The role of interoperability in sustainability decisions: the case of CDP
}

\author{
Maria Mora-Rodriguez \\ System Centre \\ University of Bristol \\ Bristol, United Kingdom \\ maria.mora@bristol.ac.uk
}

\author{
Chris Preist \\ System Centre \\ University of Bristol \\ Bristol, United Kingdom \\ chris.preist@bristol.ac.uk
}

\begin{abstract}
Climate change, pollution, deforestation and water scarcity are important problems that human activities provoke. Business decisions and actions are the major causes of environmental degradation. Decisions based on broader aspects than financial ones are required to bring solutions to these environmental challenges. For that purpose, businesses need a transformation in their management and operations. The information is critical to ensure the decision-making process, in this study we present the corporate reporting ecosystem that businesses face today. The opportunities and pending challenges that this scenario of information signifies, and the role that the interoperability, understood as the ability to exchange and use information given a heterogeneous scenario of organisations and information, could play to achieve the business transformation, in the light of the European Framework for Interoperability (European Commission, 2015), are explored. CDP (formerly known as Carbon Disclosure Project) is the relevant case studied, as it is one of the most important environmental reporting initiatives in the world. In particular, we explore the role of interoperability in CDP through interviews with 17 CDP members. These respondents being a set of companies and their stakeholders, including investors, governments, scholars and NGOs. As a conclusion, we confirm that (1) interoperability has a role to play to empower more environmental actions in businesses; (2) specific characteristics of interoperability are demanded in legal, organisational, semantic and technical levels in order to consider environmental information in decisions; (3) the need for ICT solutions to tackle interoperability challenges is mainly required in the areas of data standardization, data connectivity and data integration with applications and processes.
\end{abstract}

Keywords-Interoperability; Business transformation; Environmental Reporting; $\mathrm{CDP}$

\section{INTRODUCTION}

Degradation of the environment is a major problem currently facing humanity. It brings new challenges, as well as potential opportunities, for governments, businesses and the society. Businesses are both significant contributors to, and potential solution providers for, environmental problems. Hence, in order to reduce environmental degradation, fundamental changes in how business is conducted are necessary. We refer to this as business transformation, as defined by Elliot [1]. Such a transformation requires a deep understanding of current actual, and potential future, environmental performance of a business. This in turn requires that firms inform more and better about their environmental performances and actions, and together with their stakeholders, develop more sophisticated decision-making processes and associated information systems (IS) to support the transformation towards sustainable developments.

It is recognised that information about corporate environmental impacts can play an important role in business transformation. The details of environmental impacts of modern corporations are increasingly made public through corporate sustainability reports and other venues. The drivers for this include regulatory compliance, reputation enhancement, meeting investor demand for performance information, and fulfilling a commitment to demonstrate an ethical position to stakeholders. The disclosure of environmental information is mainly influenced by:

(1) new regulations, which define compulsory corporate information to disclosure, including environmental aspects. An example of that is the European Directive 2014/95/EU for non-financial reporting, which in 2017 applies to public interest organizations with more than 500 employees, representing approximately 6000 large companies in Europe. The Directive defines a set of information to be disclosed and suggests a set of reporting frameworks to help to comply it, such as the Eco-Management and Audit Scheme (EMAS) and International Organisation for Standardisation's (ISO 26000). How to apply the directive is a responsibility at national level: the Directive has to be transposed by each EU member into local legislation and no later than December 2016,

(2) global agreements on climate change, with initiatives like the Paris agreement that seeks to limit the global warming below $2^{\circ} \mathrm{C}$, as a result of the United Nations Framework Convention on Climate Change [2]. Nearly 200 nations signed it, and it is the responsibility of each government to decide which measures imposed to reach such targets.

(3) voluntary reporting initiatives, which help companies to support their reporting practices, identifying relevant information to disclose and manage. An example of voluntary frameworks for sustainability reporting is the Global Reporting Initiative (GRI) and Dow Jones Sustainability 
Index (DJSI), and CDP, which only focuses on environmental concerns. The latter is the primary focus of this study.

For the effective design of business transformation processes and ISs, it is important to consider the existing reporting ecosystem surrounding firms, where potential challenges and opportunities might arise. The corporate reporting ecosystem represents a complex scenario of information (Fig. 1), composed of data covering a variety of financial and non-financial topics, from different organisations, data formats (video, tweets, spreadsheet, XBRL, HTML, PDF, sensors, etc.) and reporting frequencies (annually, quarterly, real time). The main focus of that amount of data was, in the past, to satisfy certain information needs of the shareholders. Now, it is necessary to evolve from shareholders to a broad set of stakeholders, which includes almost all global public opinion. This idea is aligned with Freeman's stakeholder theory, which states that corporations need to incorporate the interests of all stakeholders and not only those with a financial part in their businesses in order to ensure their long-term success [3]. This alignment with the stakeholder means both financial and non-financial issues must be considered in corporate decision-making [4].

This ecosystem of information brings potential opportunities for business transformation, to increase the impact of environmental information on decision-making processes of companies and their stakeholders. However, challenges arise to take advantage of that ecosystem such as the lack of software systems to support sustainable decisions [22]. Several authors point out the role of interoperability as an enabler [5][6][7]. According to these authors, interoperability allows firms to effectively share and reuse existing information among interested parties by:

- the exchange and use of information between information systems,

- the definition of relationships between different data environments,

- the coordination of business processes among the various organisations and

- the coordination of different legal frameworks to allow interoperation.

The objective of this paper is to explore the role of interoperability in environmental sustainability: what is its role currently, what might it be in the future, and what is necessary to enable this. To do this, we conducted interviews with 17 members of one of the world's major environmental reporting initiatives - CDP. These members consist of a number of different stakeholder classes - companies, governments, investors, academics and NGOs.

This study is relevant to both academia and industry because it gives insights on ICT needs to build better IS and decision support solutions to overcome sustainability challenges [25][26].
The paper is organised into six sections. Section one provides a review of ICT in sustainability and the opportunities for interoperability. Section two presents CDP as a case for study. Section three describes the research questions and methodology. The results of the study and discussions are examined in the two sections that follow. We conclude with some recommendations and limitations of the study

\section{THE ROLE OF INFORMATION AND COMMUNICATION TECHNOLOGIES AND INTEROPERABILITY}

The corporate reporting ecosystem consists of a scenario in which firms and other types of interested parties meet, in order to use the available resources of information to make better decisions. Information and Communication Technologies (ICT) are essential in this ecosystem, and hence, should have a supporting influence on enabling firms to tackle the required business transformation that would help to reduce environmental degradation, as suggested by Elliot [1]. The author places ICT as the central element in a socio-technical system, which states that, in order to reduce environmental impacts, it is not only necessary that companies take certain actions, but also that an integrated approach is adopted by firms and their stakeholders, sharing understanding and activities, ICT innovation and research.

Several authors advocate that both standardisation and interoperability are indispensable to ensure the effective interpretation, exchange and use of the information among different users [8][9]. In this study, we consider both of these.

Standardisation is key to facilitate the exchange of the information, formalizing the technical requirements to ensure the quality of the information. In order to understand the relevance of standardization, the particular case of XBRL (eXtensible Business Reporting Language) is worth considering. XBRL is a standard technology mainly required by regulators and supervisory agencies in all over the world to gather financial information from large, SMEs corporations and public administration. The use of XBRL offers the following benefits [10][11]:

- XBRL offers the possibility to represent business facts, which means data contextualised under business requirements (presentation, period, legal references, calculation) and data quality.

- XBRL enables a good level of interpretation, given the detail of the data represented.

- XBRL make easier the accessibility and integration of the information to any application or management process, as it is an open standard.

- XBRL enables the validation and comparability of information

XBRL is used primarily for the exchange of financial information, though increasingly pilots are experimenting with its use for other aspects of reporting. 


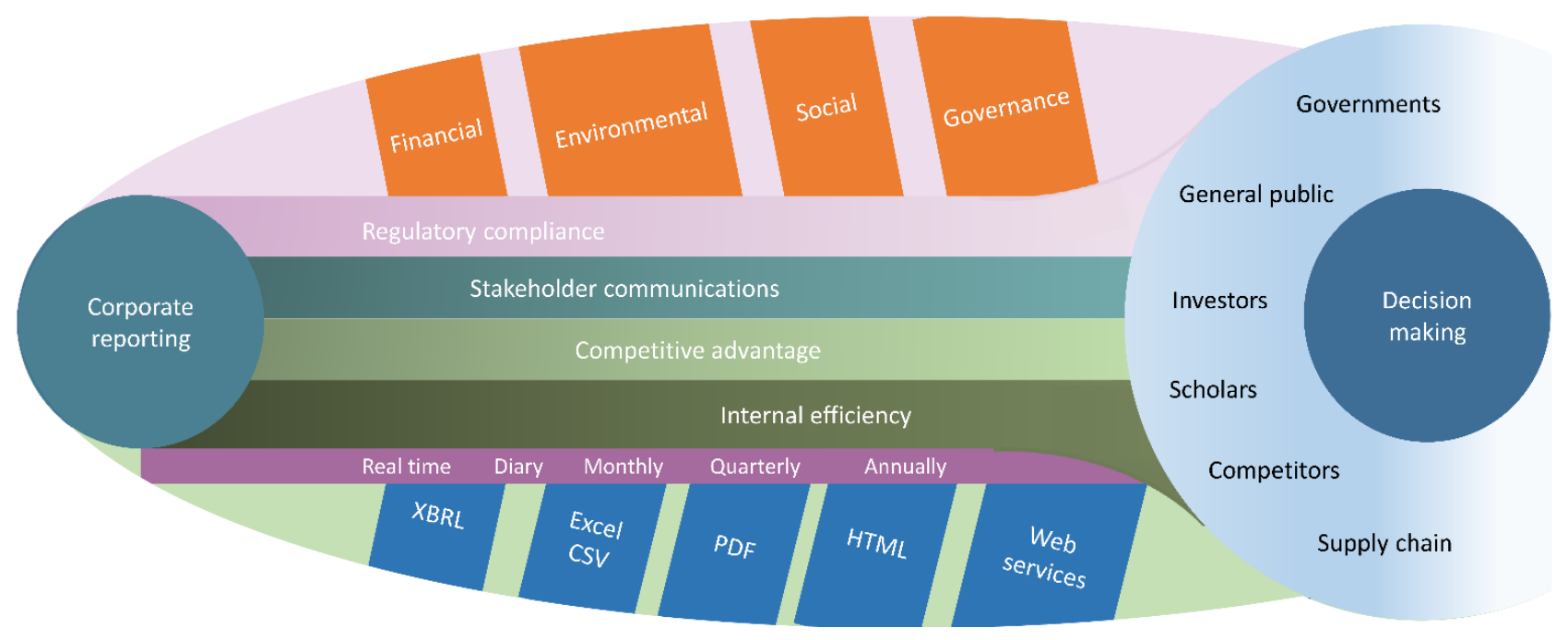

Fig 1. Corporate reporting ecosystem

However, standardisation is not enough to ensure effective interpretation, exchange and use of information, between people, organizations, processes and systems in the corporate reporting ecosystem. As this data scenario implies a greater level of complexity, generated by the heterogeneity of the organisations and information involved, different information content, data formats, data frequencies and ways of access, it brings to light additional challenges which require interoperability beyond simply a shared standard.

Initially, interoperability is defined by the IEEE as the "ability of a system or a product to work with other systems or products without special effort on the part of the customer. Interoperability is made possible by the implementation of standards". The concept of interoperability has evolved, and it is understood today as the ability to exchange and use information given a heterogeneous scenario of organisations and information [12], beyond the merely technical layer. Various frameworks have been proposed to define the different layers in which interoperability takes place, grounded in the following two goals:

(1) Practical: the ability to exchange and use information between systems. For example, Software as a service solution (SaaS) at the application level, syntactic and semantic interoperability.

(2) Organisational: the ability to coordinate organisations for mutual benefit. For example, through legal and statutory agreements.

In the particular case of the European Commission [13], the European Interoperability Framework is issued to enable effective communication between public administrations in the 28 Member States. This framework is considered key in the future European strategic plans towards the consolidation of a unique economy and the Digital Single Market [14]. It covers the prac- tical and organisational scopes described above, distinguishing the following four layers of interoperability:

(1) Technical interoperability: it involves the definition of technical specifications to ensure the communication between computer systems and services. It includes messaging protocols, data formats, security and services descriptions and properties to ensure the quality of the information, such as consistency, completeness and reliability.

(2) Semantic interoperability: it covers the technical mechanisms to define the meaning and the relationships between different sources of information, avoiding ambiguous interpretations (same data, same interpretation). For example, data dictionaries, schemas and taxonomies.

(3) Organisational interoperability: coordinates the organisational processes to integrate into the internal management and strategies. Involves Memorandum of Understanding $(\mathrm{MoU})$, and the definition of expected level of agreements.

(4) Legal interoperability: It implies legal agreements to allow the compatibility between different legal conditions in order to access and use information. For example, it involves the definition of appropriate privacy terms to cover the needs of different legal environments involved.

Given the relevance of this framework in the future of the European economy, and for the purpose of this study, we analyse our later results in terms of these four layers.

\section{THE CASE OF CDP, AN ENVIRONMENTAL REPORTING INITIATIVE AND A SOURCE OF ENVIRONMENTAL DATA}

CDP is a leading organization in the environmental reporting field. Since 2002, it has collaborated with companies, investors, NGOs, governments and cities from all over the world, helping them to disclose, measure, manage and share their environmental impact, awareness and actions. As an organisation, the CDP proposes three objectives to achieve environmental sustainability: (1) to reduce GHG emissions; (2) to reduce wa- 
ter scarcity; (3) and to prevent forest destruction [15]. CDP has captured a considerable attention from investors, reporting firms and cities, with more than 800 engaged investors, 4500 reporting companies and 110 cities worldwide in 2015 . It is a global initiative dedicated to collect data from large corporations, SMEs and cities through its climate change, water and forest programmes, also offering tools and services to facilitate the use of its data. For each programme, a questionnaire is sent to companies on behalf of institutional investors that endorse CDP work and support the disclosure requests of each programme. Each questionnaire is an independent data channel, whose completion depends on companies' decisions, meaning that not all companies disclose to all three programmes.

As a result, CDP now holds the largest collection globally of information on climate change, water and forest impact of corporations, with the aim of supporting investors in better understanding associated risk and encouraging long-term business transformation towards sustainability.

CDP as an organisation is active in increasing the consistency and alignment of its data with others reporting organisations and frameworks. This organisational cooperation takes form of MoUs and technical documents which detail the levels of alignment between CDP data and other reporting frameworks. Currently, CDP maintains collaboration lines to align areas of reporting with organisations such as GRI and DJSI. The main goal is to enable users and reporting firms to refer to the same data points through different reporting channels. It represents a significant step towards the global standardisation of environmental reporting.

CDP offers one of the most comprehensive corporate environmental datasets in the world, which is useful to a multitude of companies and other stakeholders, although it is not yet clear what the real use and impact of this data is on decision makers. Questions arise regarding the place of CDP as an environmental data provider in the corporate reporting ecosystem and its impact on decision makers, and how interoperability can bring new opportunities to drive the business transformation considering the role that CDP plays. We consider CDP relevant for this study because:

- It offers a framework to disclose environmental information to companies and cities from all over the world, effectively driving information standardization;

- It has a voluntary reporting system which centralizes standardized environmental information;

- It provides its data to decision makers in the expectation that they use it to inform their actions;

- It is an environmental reporting initiative which puts environmental information at the heart of financial decisions making, to reduce environmental degradation.

- It is a reporting initiative [29][30][32] and a source of data explored in the literature [31][33][34].

\section{RESEARCH QUESTIONS AND METHODOLOGY}

The key research question of this study is:
How does interoperability support stakeholder decision towards sustainable actions currently, and how can it enhance such decisions in the future?

Given the relevance of the corporate reporting ecosystem and the role that CDP plays, qualitative empirical data were collected via semi-structured interviews with experts from 17 stakeholder members of CDP. The panel of experts was composed of representatives companies, governments, investors, academics and NGOs. The participants include data analysts and departmental managers with a deep understanding of environmental and corporate data. In order to maintain the anonymity of the participants, only the number of organisations per group has been identified (TABLE I).

\begin{tabular}{|l|c|}
\hline Stakeholder group & Participants \\
\hline Companies & 5 \\
\hline Investors & 4 \\
\hline Governments & 2 \\
\hline Academia & 4 \\
\hline General public, NGOs & 2 \\
\hline Total & 17 \\
\hline
\end{tabular}

TABLE I: Number of participants per group interviewed

The interviewees received the questionnaire about one week in advance, including a brief introduction to the study. During six months, the interviews were conducted face to face and via video-conferences, then were recorded and transcribed.

\section{RESULTS}

The interviews identified that the main motivations that encourage companies to disclose and use environmental information from CDP are the inclusion of better environmental strategies in their decisions, strengthen their stakeholder communications and enhance their reputation. In case of investors, their main driver is to get more accuracy on financial risks assessment, with a clear impact on sustainability methodologies for company evaluation. Research on environmental accountability, company's environmental profile and financial impacts are the main areas of interest for academics. NGOs normally use the environmental information provided by CDP to increase the awareness of environmental stewardship in society and businesses, with a clear impact on stakeholder communications.

As our objective is to explore the role of interoperability in stakeholder analysis and decisions, we identified in the interviews the ways in which they used the environmental information provided by CDP.

Companies and their stakeholders normally use their proprietary tools to analyse CDP data. Those tools are more integrated with their operational and decision-making processes. Some companies are also interested in using the analytical tools offered by CDP because these tools help them to complete the 
questionnaires and carry out accurate benchmarking analysis against their competitors and peers. In the majority of the cases, these analyses are used for public communications and board reports.

The majority of the participants excepts NGOs support their decision-making processes and management using stock market data, financial reports, annual reports and other sources of financial and economic information. As a second priority, they are considering social and environmental impacts in their evaluations through sustainability reports, annual reports and CDP data. They are evolving towards making decisions supported by financial, social and environmental information as a whole.

Investors, governments and some academics support their analyses and researches using external data platforms, such as Bloomberg and Sustainalytics, because of their high financial credibility. Stakeholders see valuable in having CDP data integrated into those platforms. However, they complain about the lack of a better integration. They consider CDP data deep and with a high level of detail, properties that they can not find when they are accessing the CDP data using some of the data platforms. In some cases, these platforms simply link to CDP reports, rather than being properly integrated.

In general, when companies and stakeholders consume nonfinancial information, they criticise the absence of a verification and audit process. This is also the case of the CDP data. One of the techniques they use to verify certain CDP data is to cross-check with other sources of information where the same data appear, checking if the information is the same. For example, cross-checking carbon emissions figure using annual reports based on GRI framework and CDP reports. In that particular case, CDP has an agreement with GRI in the form of a $\mathrm{MoU}$ and technical documents. However, participants found that both frameworks need a deeper level of harmonization regarding methodologies, units, level of aggregation, data formats and unique identifiers.

The results of the interviews were coded following [16][17][18] recommendations in order to provide emerging patterns of themes. After two rounds of coding exercise, we categorised the results in different interoperability properties, evaluating the attitude of the participants towards interoperability considering the need and current practices mentioned by each participant, addressing the four layers of interoperability (legal, organisational, semantic and technical).

, As a result, a set of interoperability properties demanded or adopted by the participants to include environmental information in their decision-making processes were identified. We consider an interoperability property as any feature needed to address any layer of interoperability. The set of properties is presented in TABLE II, classified under the correspondent interoperability layer and the participant that made mention.

The results allow recognising a set of interoperability properties that enable measuring the attitude of companies and their stakeholders towards interoperability and determine how relevant each layer is. During the next sections, we explain in detail our interview findings with regard to each interoperability property.

\section{A. Legal interoperability}

The analysis of the results suggests that the participants consider two aspects of legal interoperability to be relevant.

- Policy integration. The concept of interoperability in policy is defined by the level of compatibility with datasets evaluated for decisions. Some companies, investors and academics did mention that they evaluate legal conditions in order to determine the level of compatibility with the current datasets considered for their decisions, as policies can demand new information flows, which can be relevant or not to integrate within their analysis. [Government 2] "Another analysis we do is tracking what is being done at the company corporate level and how it links to national policy level. We are interested in evaluating the impacts of company actions on traceability at national level". Mainly, investors, governments and academics consider it pertinent to assess how the companies that respond to CDP comply with regulations at national and global levels in order to determine how confident they are in the direction they are taking. [Investor 1] "As part of our company's evaluation criteria, we analyse the level of commitments with governments and if they are ready for future regulations".

- Policy compliance. For companies, the policies have an impact on the environmental actions they take and the information they need to disclose to certain authorities. It constantly affects their reporting processes, meaning more data to store and more information to communicate. [Company 4] "Reporting is not a standalone thing, and we have constant reporting influences with impact on operations. These actions that we are taking, we talk and report about. We also have to comply with legal regulations, so we need to feed into that channel as well".

\section{B. Organisational interoperability}

As organisational interoperability, there are two levels of coordinations demanded by the participants: (1) more focus on the convergence of CDP data with other reporting standards, and (2) closer work of CDP with companies to help them align environmental strategies within their departments.

- Link CDP information with other global standards. The majority of the participants agree that CDP should align strategies and content with other reporting organisations, mainly with the most recognised sustainability frameworks 


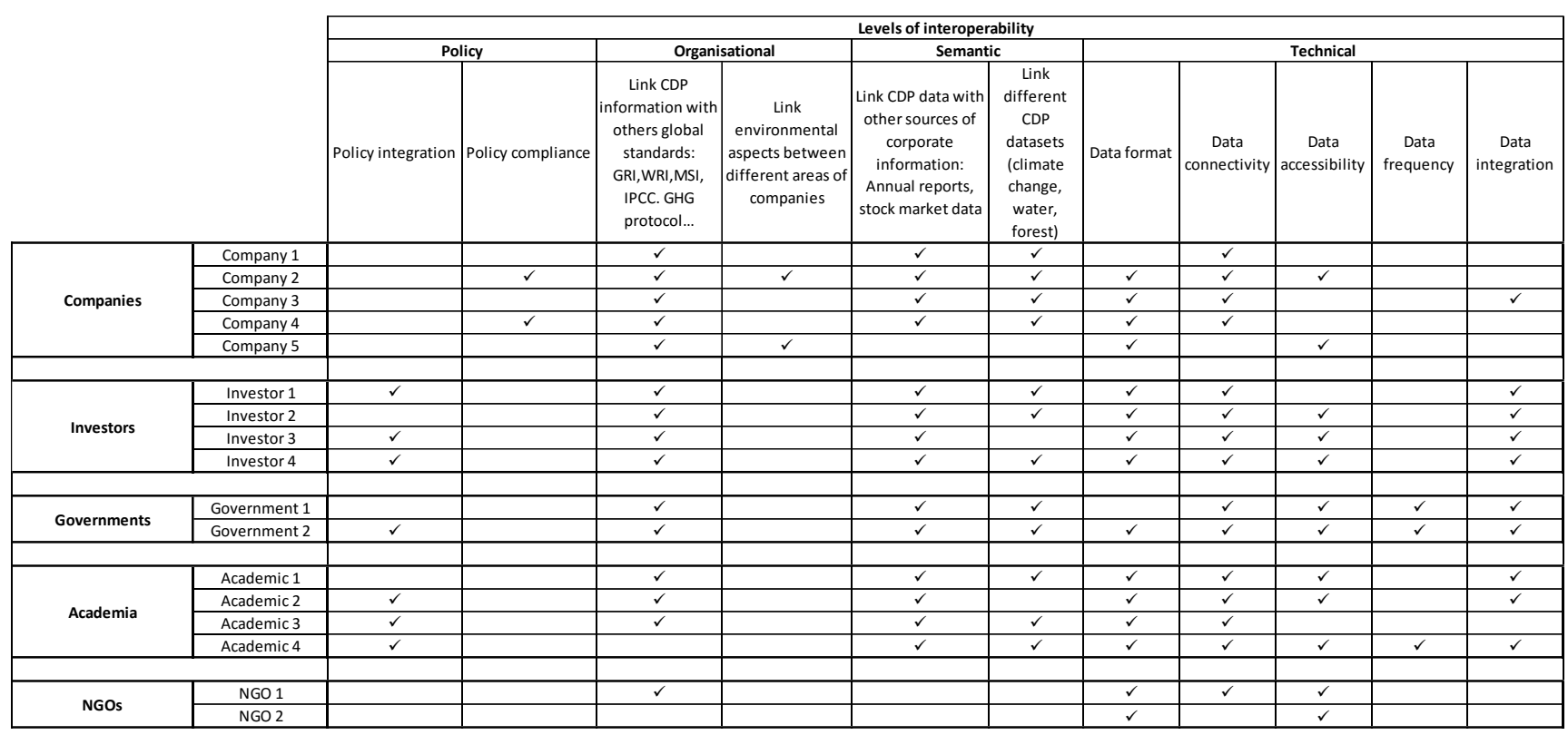

TABLE II: Interview results and interoperability properties

in the market. From the company's perspective, this would represent an improvement for them during their disclosure process, as aligning the different frameworks that they use to support their corporate reporting means they do not need to make any additional effort to report and control the same information in different ways. [Company 3] "We do not only disclosure to CDP, also we use GRI framework to generate our sustainability report. There are certain indicators from the environmental section of GRI aligned with $C D P$, however, the way the information is asked, in term of level of aggregation, units and methodologies are completely different. So we need to make a double effort to report sometimes the same information in different ways". Users of the data demand to CDP a major alignment with others frameworks that CDP shares areas of interests and content, in order to facilitate better validations by allowing cross-checks between common data points. The reason for that need is because they criticise the absence of verification and audit processes of the CDP data. They also mentioned that in order to facilitate the consumption and combination of data from multiple frameworks and get more complete information for decisions, there is a lack of technical agreement between organisations regarding data formats, content, level of aggregation and unique identifiers of companies. [Investor 1] "Ideally, we would like to integrate CDP responses with GRI, WRI and SASB information available, and evaluate the overlay of both responses and results. That would be useful to consider nonfinancial information in our most relevant decisions. Currently, we can not do that level of analysis, because each dataset is published with different formats, structures, locations and content. Moreover, it requires a manual process to find levels of alignments to analyse."
- Link environmental aspects within different areas of companies. Reporting companies find it difficult to engage key departments within organisations on environmental concerns, in order to get a more integrated environmental assessment and management to disclose to CDP. The interoperability of environmental information, aligning environmental reporting within different areas of companies is demanded, but the lack of common environmental interests and concerns are presented as main barriers. [Company 5 ] "We found CDP useful because it helps us to understand the value of considering certain environmental aspects of our business. However, it is still difficult to cover all the points demanded by CDP due to the dependencies with other departments of my company, which are not aligned with that level of environmental concerns and, therefore, management".

\section{Semantic interoperability}

After identifying the legal and organisational mechanisms demanded by the participants in order to make better use of CDP data in their analysis and decisions, there are two main semantic requirements distinguished:

- Link CDP data with other corporate datasets. The majority of the participants except NGOs would like CDP to facilitate the connection of its dataset with other corporate information publicly available, such as financial reports, stock market data, corporative website and social media profiles. Since for them, these types of data sources are the most useful to carry out analysis and contextualize findings. [Government 2] "I think what is really important for us is to contextualize the CDP data. To tell a nice story is very useful for us... for example, demonstrating that there are numbers of companies taking actions representing the revenue at a certain amount. That provides very powerful 
statements...But to be honest, it is difficult for us, as we have to put together certain company data such as revenues, total of employees, assets in management, which is difficult and time-consuming. If CDP can provide that information, it would be very helpful". However, the lack of alignment in data formats, unique identifiers, data frequencies and the lack of accessibility of the data are mentioned as the principal difficulties to carry out deep analysis considering multiples datasets. Connecting pieces of information on the same company from different data sources requires semantic alignment to take place.

- More integration across the different CDP datasets. Publishing the climate change, water, forest and scores datasets integrated into one is regarded as an important improvement for CDP by companies, investors, governments and academics. As potential users of the information, they expect from CDP to get relevant information about company's environmental profile. However, CDP deals with each dataset separately, collecting the information via three different questionnaires, whose information is not linked, meaning that CDP does not offer an integrated environmental profile where, for instance, company's risks can be evaluated by water, climate change and forest aspects. In order to do that, stakeholders need to work with each dataset separately and to consider difficulties like the fact that companies do not necessarily respond to the three questionnaires. [Investor 1] "Would like to see more integration of CDP datasets. At the moment, water, forest and climate change appear separately, which is not very useful for us when we need to evaluate the environmental profile of any company". Likewise, companies want CDP to publish the scores linked to the firms' responses at question level, to facilitate their learning from the leaders. What they want is to look at the best answers from leaders and learn from their actions and strategies. [Company 3] "We analyse every question, and we look at best practices in companies with better scores, looking at which their strengths are and what changes could make in our work, adapting our strategies slightly. We get very nice ideas that can be adapted to our company".

\section{Technical interoperability}

During the previous results, several technical needs were mentioned as requirements to reach other levels of interoperability. Concretely, these are the technical interoperability properties identified:

- Data format. Most of the participants find difficult to carry out deep analysis combining CDP data with others datasets, comparing multiples companies and data points. The main criticism is that none of the formats and data structures provided by CDP are easy to analyse, consume or integrate with their internal systems and processes, normally requiring an additional effort to translate the data into something easier to deal with. [Academic 3] "When I look at a company response PDF format, I know it is typi- cally 40 pages. The qualitative data is very difficult to read, it is very difficult to copy and put in a different format as the formatting is locked. ... Probably my biggest criticisms is not the content, it is the format of the content." "At the moment CDP just offer a flat dataset and a confused spreadsheet which are not being used in a way which is intelligent."

- Data connectivity. The participants are interested in having technical solutions to help them to consume different types of information from companies. For example, they would like to know how to link CDP responses with other sources of information which refer to same companies, like stock market data and sustainability reports. In that way, they want to add more value to their analysis, mostly contextualising financial and environmental impacts. Also, they demand technical facilities to find common data points that CDP shares with other reporting frameworks like GRI. Meaning that, if a company discloses their carbon emissions in their annual report and also in CDP, they can have the capacity to cross-check both sources of information for validation purposes. Some academics pointed out that the goal of CDP is not to provide datasets for financial research. However, the audience of CDP demands the match between CDP data and financial information. The main challenges recognised are the lack of harmonisations between datasets and get unique identifiers in corporations.

- Data accessibility. The general trend is that companies and their stakeholders do analysis using internal tools and techniques. Mostly academics, governments, investors and companies find a barrier to be the lack of an automatic way to access the CDP data, with functionalities to filter the content. They found this solution necessary to facilitate the consumption and analysis of the CDP data.

- Data frequency: some investors and academics, and most governments consider as a constraint to have the CDP data on an annual basis. For their progress analysis and assessments, they would like to have data on quarterly or monthly basis, aligned to financial obligations, in order to make more accurate decisions. [Government 1] "Data on an annual basis is not enough to show the momentum. We need data to check company and city progress and commitments over the time. That is the way to see what it is going on and how things are going to happen".

- Integration with existing data platforms. Investors, academics, governments found useful the integration of CDP information in data platforms like NAZCA, Bloomberg, Sustainalytics, Thomson and Reuters. [Investor 1] "Due to CDP data can be accessed via Bloomberg terminal, which is one of the reasons why it is useful for us. Because if I am in Bloomberg, I do not want to go off and go to other website and log in, to pull all the data. That is the reason why is so useful, just thinking that having more and more information in what future companies are disclosing, makes 
us think in more sophisticated ways to measure and monitor, in order to quantify some of the ESG issues. We will have the need to have more datasets in one place". However, in some cases, the CDP data integrated into these platforms is not enough and does not cover stakeholders demands. [Investor 3] "In Sustainalytics, there is data related to $C D P$, whether the company respond to $C D P$ or not. However, we do not have immediate access to what the company responds. In that case, we need to get the access to the data through $C D P$ ".

\section{DISCUSSION}

Results partly accord with some of the conclusions from the literature regarding the role of ICT in environmental sustainability, namely with respect to constraints on data quality, reliability of data, and the lack of adequate IS for engaging stakeholders with this information, as is mentioned below by some authors:

- Lack of IS to capture and manage environmental information [35].

- $\quad$ Better data quality and more reliability [31][33].

- Lack of verification and audit processes [31][36].

The results also demonstrate that interoperability has a role to play to achieve business transformation. Mainly at the development of decision-making processes and associated IS, where particular social-technical properties under the influence of general developments in ICT are required to drive long-term decisions, with impact on strategy and management processes. Concretely, it is required a major level of technical formalization, in terms of convergence and applicability of environmental initiatives like CDP with other reporting organisations, data providers and areas of companies. Moreover, it is necessary to have ICT solutions to exchange data in a meaningful manner and make the data more accessible to a broader community, by means of a major harmonization and integration with external applications and organisational processes. The results show that in order to achieve a major harmonization and integration, aspects such as data standardization, data connectivity, data accessibility and data integration with external applications must be considered. These results contribute to ICT for sustainability and sustainable decision support systems studies [22][23][24], identifying also concrete information systems properties required by real users of environmental information.

Looking at the context where they use CDP data, we have discovered that interoperability is implicitly considered in policy, organisational, semantic and technical levels. Likewise, we found that CDP has some work to do in order to bring new opportunities offering the full potential of its information, concretely:

- A major policy engagement: Policy represents more environmental information to store and disclose by companies, and more data to evaluate for decisions by their stakeholders. If CDP increases its level of interoperability with coming regulations, defining what its level of compatibility and impact is, it will help reporting companies during their disclosure process and also their stakeholders in making better decisions. A better policy engagement with coming regulations brings opportunity to CDP in order to increase the value and impact of its data.

- More detailed organizational agreements: CDP should agree and define with further detail the level of alignment of its data with other frameworks that CDP shares areas of interest. MoUs and current technical specification are not enough. It would be necessary to define more concrete details about data formats, content and scope, transformations and the levels of aggregation. In that way, companies would not need to report same information in different ways, depending on the final report (CDP report, annual report, sustainability report, etc). Being more concrete on this alignment brings more credibility and reliability of CDP data, facilitating the cross-validation with external data sources to companies and their stakeholders. Also, CDP should work more closely with companies to help them improve engagement and integration on environmental aspects within their different departments. Better integration and management of environmental aspects in companies would enhance environmental data quality. However, that represents an additional effort for CDP, given the variety of reporting companies from different sectors, sizes, countries that already disclose to CDP.

- $\quad$ Enable better semantic interoperability: The need for using and analysing CDP data in relation with other datasets from financial, social and environmental topics is a common demand for the majority of companies and their stakeholders. The reality is that combining CDP data with other corporate datasets or corporate reports is difficult and almost impossible for the majority. The main problems detected are the lack of harmonization between the different datasets regarding data formats, content, data frequencies and unique identifiers. One of the solutions that CDP can address is to offer its data in different data formats considering how other data sources are presented and which formats are familiar to the CDP audience. For example, CDP could provide its data openly and in open standards format, such as the XBRL format, as some of the reporting companies disclose their financial information to regulators like the U.S Security Exchange Commission [19] in XBRL format and investors are familiar with analysing XBRL information for their decisions. Furthermore, maybe CDP could offer to companies the possibility to submit some of its data related to targets on a more frequent basis, it will help to use the information for monitoring purposes. Finally, CDP should make accessible its data linked to other sources of information or presents its data with company's unique identifiers and teach the audience how to use it to combine with other sources of information. In overall, the semantic interoperability in CDP will help to evolve decisions mainly supported by financial information to consider also social and environmental aspects. 
- Better technical solutions: There are three types of technological aspects demanded of CDP. Firstly, to introduce standards formats to facilitate the exchange and combination of CDP data with other sources of information. The need to standardise data in CDP brings up the possibility to adopt XBRL in non-financial data. Also, publishing CDP data linked to other structured data, using best practices in semantic web such as Linked data [20], could be an interesting solution to explore. Secondly, CDP should provide access to its data in an automatic way, enabling a better integration with external applications and internal processes. Ideally, CDP should make its data accessible, including the ability to retrieve and manipulate. Solutions based on an Application Programme Interface (API), Web services or semantic interface for queryings, such as SPARQL [21], that enable users to write queries to get access to the data and its links to other data sources. Finally, it would beneficial to have better integration of CDP data with external data platforms, such as NAZCA, Bloomberg and Sustainalytics, in order to bring value to decisions. In that case, CDP should work more closely with data providers to transmit the full value of the data. CDP should be more active in encouraging data providers in how CDP data can be presented and used through these external platforms.

\section{CONCLUSIONS}

We explored the role of interoperability in sustainable decisions, taking as a case of study CDP and conducting interviews to a set of companies and their stakeholders, including investors, governments, academics and NGOs. They represent users and disclosers of environmental information. As a result, the following three learnings arise:

(1) Current reporting trends and demands from companies and their stakeholders, and the place of environmental concerns in decision-making processes.

(2) A set of interoperability properties are demanded to consider environmental information in decisions.

(3) CDP has a role to play in environmental sustainability decisions, but CDP has some work to do considering interoperability properties in order to bring the full potential of its data to their users.

Companies and their stakeholders demonstrate that their reporting trends are evolving to take advantages that the corporate reporting ecosystem provides. Their decision-making and management processes consider financial, social and environmental aspects from corporate reports, other sources of information and data platforms. However, challenges arise in order to carry out a better use of the information available for taking decisions and achieve the business transformation. Interoperability properties need to be considered to achieve the transformation, concretely we demonstrate that legal, organizational, semantic and technical interoperability are deemed to increase the value of environmental information for decisions. As a con- tribution to ICT for sustainability studies, the need for ICT solutions to overcome these interoperability demands are highlighted in the areas of data standardization, data connectivity, data accessibility and data integration.

From an industry perspective, the results demonstrate that CDP is doing well supporting companies to inform their stakeholders about their environmental performances and strategies. Likewise, the information centralised by CDP represents a substantial resource of information for the decision-making processes in companies and their stakeholders. However, CDP needs some additional work to bring the full potential of its data in such processes and influence in actions. In summary, the study suggests that CDP should increase its level of interoperability with coming regulations, other reporting organizations and respective frameworks, defining more concrete details about its links with other sources. Also, CDP should provide a major integration within its different datasets (climate change, water and forest) and introduce the ICT solutions mentioned above to address these interoperability demands.

As a further research, it would be valuable to explore the kind of decisions that interoperability could drive, given the corporate reporting ecosystem. We believe that our study can facilitate the identification of design patterns to build better IS solutions for sustainability, in the line with the efforts like those of Knowles [27][28]. Likewise, would be worth exploring the role that certain technologies can play, given the interoperability demands in order to support decisions, such as XBRL for standardization and semantic meaning. For example, what value can XBRL bring to environmental reporting initiatives like $\mathrm{CDP}$, considering the role that these initiatives play in companies and their stakeholders, and their influences on decisionmakings and actions. Additionally, given the corporate reporting ecosystem, and the interoperability demands from companies and their stakeholders, it would be interesting to identify main opportunities and barriers facing business transformation, exploring in detail solutions like XBRL in combination with Linked data and SPARQL - Linked Data for connecting pieces of information from heterogeneous data environments, and SPARQL for retrieving and manipulating linked information.

\section{ACKNOWLEDGEMENT}

This work was supported by the Systems Centre at the University of Bristol and the EPSRC funded Industrial Doctorate Centre in Systems (Grant EP/G037353/1) and CDP Worldwide, London, UK.

\section{REFERENCES}

[1] S. Elliot "Transdisciplinary perspectives on environmental sustainability: a resource base and framework for IT-enabled business transformation." Mis quarterly 35, no. 1, 2011: 197236.

[2] COP21. United Nations Conference of the Parties, 21st session; Framework Convention on Climate Change FCCC Adoption of the Paris Agreement, 2015, Paris: UN 
[3] R. E. Freeman "A stakeholder approach to strategic management." Darden Graduate School of Business Administration, 1984.

[4] O. Salzmann, A. Ionescu-Somers and U. Steger "The Business Case for Corporate Sustainability: Literature Review and Options". European Management Journal, 2005, 23(1):27-36.

[5] N. Ide and J. Pustejovsky. "What does interoperability mean, anyway? Toward an operational definition of interoperability for language technology." Proceedings of the Second International Conference on Global Interoperability for Language Resources. Hong Kong, China. 2010.

[6] H. Panetto and J. Cecil. "Information systems for enterprise integration, interoperability and networking: theory and applications". Enterprise Information Systems, 2013,7(1), 1-6.

[7] S. Nativi, P. Mazzetti and G.N. Geller. "Environmental model access and interoperability: The GEO Model Web initiative." Environmental Modelling and Software, 2013. 39, 214-228.

[8] I. Mezgár and U. Rauschecker. "The challenge of networked enterprises for cloud computing interoperability". Computers in Industry, 2014, 65(4), 657-674.

[9] A. Soltysik-Piorunkiewicz and J. Banasikowska. "Interoperability and Standardization of e-Government Ubiquitous Systems in the EU Member States". European Conference on e-Government, June 2013, p. 481.

[10] J. Mora-Gonzálbez and M. Mora-Rodríguez. "XBRL nd integrated reporting: The Spanish accounting association taxonomy approach". The International Journal of Digital Accounting Research, 2012.

[11] E. Bonson-Ponte, T. Escobar-Rodriguez and F. Flores-Munoz. "The role of metadata language implementation in the European banking supervision network". International Journal of Networking and Virtual Organisations, 2007, 4(3), 245-256.

[12] IEEE, 2015 http://bit.ly/1RyeAfE [Accessed in April 2016]

[13] European Commission. "Communication from the commission to the European Parliament, the council, the European Economic and social committee and the committee of The Regions: Towards interoperability for European public services". European Commission, 2010, vol. COM, 12/16/2010,pp. 1-55.

[14] European Commission, "Communication from the Commission to the European Parliament, the Council, the European Economic and Social Committee and the Committee of the Regions, A Digital Single Market Strategy for Europe". European Commission, 2015, COM(2015) 192 final.

[15] CDP. "Sector insights: what is driving climate change action in the world' s largest companies ? Global 500 Climate Change Report 2013 The evolution of CDP”. CDP, September 2013, 160.

[16] S. Rao and C. Perry. "The impact of internet use on inter-firm relationships in Australian service industries". Australasian Marketing Journal, 2013, 11(2), 10-22.

[17] J.S. Jasperson, T.A. Carte, C.S. Saunders, B.S. Butler, H. J. Croes and W. Zheng. "Power and information technology research: a metatriangulation review". MIS quarterly, 2002, 26(4), 397-459.

[18] M. Q. Patton. "Qualitative Evaluation and Research Methods". Sage Publications, 1990.

[19] U.S Security Exchange Commission, 2015 http://sec.gov [Accessed in April 2016]

[20] Linked data, 2015 http://linkeddata.org/ [Accessed in April 2016]
[21] W3C, 2008 https://goo.gl/8KvJJW [Accessed in April 2016]

[22] Stefan, D. and Letier E. "Supporting Sustainability Decisions in Large Organisations." ICT4S. 2014

[23] Hilty, Lorenz M., and Bernard Aebischer. "Ict for sustainability: An emerging research field." ICT Innovations for Sustainability. Springer International Publishing, 2015. 3-36.

[24] Grabot, Bernard, and Thomas Schlegel. "Editorial: ICT for sustainability in industry." Computers in Industry 65.3 (2014): 383-385.

[25] Penzenstadler B. ICT4S 2029: What will be the Systems Supporting Sustainability in 15 Years? ICT4S. 2014

[26] Cappiello, Cinzia, et al. "Eco-Reports in Clouds." ICT4S (Workshops). 2014.

[27] Knowles, B. et al. "Patterns of persuasion for sustainability." Proceedings of the 2014 conference on Designing interactive systems. ACM, 2014.

[28] Knowles, B. et al. "Design Patterns, Principles, and Strategies for Sustainable HCI." Proceedings of the 2016 CHI Conference Extended Abstracts on Human Factors in Computing Systems. ACM, 2016.

[29] Beder, S. Suiting themselves. How corporations drive the global agenda. Earthscan: London, 2006.

[30] Wegener, M., Elayan, F. a., Felton, S., and Li, J. Factors Influencing Corporate Environmental Disclosures. Accounting Perspectives, 2013. 12(1), 53-73. doi:10.1111/1911-3838.12007

[31] Andrew, J., \& Cortese, C. Accounting for climate change and the self-regulation of carbon disclosures. Accounting Forum, 2011. 35(3), 130-138. doi:10.1016/j.accfor.2011.06.006

[32] Gallego-Álvarez, I., Rodríguez-Domínguez, L., and GarcíaSánchez, I.-M. Study of some explanatory factors in the opportunities arising from climate change. Journal of Cleaner Production, 2011. 19(9-10), 912-926. doi:10.1016/j.jclepro.2011.02.012

[33] Sullivan, R., and Gouldson, A. Does voluntary carbon reporting meet investors' needs? Journal of Cleaner Production, 36(January), 2012. 60-67. doi:10.1016/j.jclepro.2012.02.020

[34] Rankin, M., Windsor, C. and Wahyuni, D. An investigation of voluntary corporate greenhouse gas emissions reporting in a market governance system: Australian evidence. Accounting, Auditing \& Accountability Journal, 2011. 24(8), 1037-1070. doi:10.1108/09513571111184751

[35] Ahmed, M. D. and Sundaram, D. Sustainability modelling and reporting: From roadmap to implementation. Decision Support Systems, 2012. 53(3), 611-624. doi:10.1016/j.dss.2012.02.004

[36] Diez, E., \& Mcintosh, B. S. Organisational drivers for, constraints on and impacts of decision and information support tool use in desertification policy and management. Environmental Modelling and Software, 2011, 26(3), 317-327. 